Article

\title{
Cellulose Nanocrystals Obtained from Cynara Cardunculus and Their Application in the Paper Industry
}

\author{
Valentina Coccia *, Franco Cotana ${ }^{\dagger}$, Gianluca Cavalaglio ${ }^{\dagger}$, Mattia Gelosia ${ }^{\dagger}$ and \\ Alessandro Petrozzi
}

CIRIAF, University of Perugia, via G. Duranti, 67, 06125 Perugia, Italy; E-Mails: cotana@crbnet.it (F.C.); cavalaglio@crbnet.it (G.C.); gelosia@crbnet.it (M.G.); petrozzi@crbnet.it (A.P.)

$\dagger$ These authors contributed equally to this work.

* Author to whom correspondence should be addressed; E-Mail: coccia@crbnet.it;

Tel.: +39-075-585-3615; Fax: +39-075-515-3321.

Received: 28 May 2014; in revised form: 29 July 2014 / Accepted: 6 August 2014 /

Published: 13 August 2014

\begin{abstract}
Biorefinery aims at designing new virtuous and high-efficiency energy chains, achieving the combined production of biofuels (e.g., bioethanol) and biobased products. This emerging philosophy can represent an important opportunity for the industrial world, exploiting a new kind of nano-smart biomaterials in their production chains. This paper will present the lab experience carried out by the Biomass Research Centre (CRB) in extracting cellulose nanocrystals (NCC) from a pretreated (via Steam Explosion) fraction of Cynara cardunculus. This is a very common and invasive arboreal variety in central Italy. The NCC extraction methodology allows the separation of the crystalline content of cellulose. Such a procedure has been considered in the literature with the exception of one step in which the conditions have been optimized by CRB Lab. This procedure has been applied for the production of NCC from both Cynara cardunculus and microcrystalline cellulose (MCC). The paper will discuss some of the results achieved using the obtained nanocrystals as reinforcing filler in a paper sheet; it was found that the tensile strength increased from $3.69 \mathrm{~kg} / 15 \mathrm{~mm}$ to $3.98 \mathrm{~kg} / 15 \mathrm{~mm}$, the durability behavior (measured by bending number) changed from the value 95 to the value 141, and the barrier properties (measured by Gurley porosity) were improved, increasing from $38 \mathrm{~s}$ to $45 \mathrm{~s}$.
\end{abstract}

Keywords: biobased product; biorefinery; cellulose nanocrystals; residual biomass; steam explosion; paper industry 


\section{Introduction}

Lignocellulosic biomass is a potential source of saccharides that can be converted into alternative fuels as bioethanol. Concerning this aspect, a relevant ongoing experimental program is dedicated to producing bioethanol from residues at CRB labs [1-4] but also on other energy-from-biomass production technologies $[5,6]$.

Focusing on the bioethanol conversion, it is typically accomplished through the production of hexose and pentose sugars from cellulose and hemicelluloses [7]. In this context, an important aspect to be disclosed (as starting point) is the biomass initial characterization in terms of cellulose, hemicelluloses and lignin content. Several literary studies are available showing the processing of a ligno-cellulosic biomass and calculation of the energy-materials yields obtainable from energy treatments. In higher plants, cellulose plays an essential role as a reinforcing element in the cell wall, generally together with lignin and hemicelluloses. These three polymers are closely associated making up ligno-cellulosic biomass, and the relative content of cellulose and lignin vary among species [8].

The presence of lignin in the plant cell wall, together with the partially crystalline nature of cellulose fibers, results in formidable challenges to deconstruct the lignocellulose matrix and depolymerise its cellulosic content $[9,10]$.

Microfibrils are cellulose chains, around $20 \mathrm{~nm}$ wide and several micrometers long that consist of alternate crystalline and amorphous domains. Due to extensive inter- and intra-molecular hydrogen bonds by glucosidic hydroxyl groups, the crystalline domain is packed closely and results in an area of high crystallinity.

Cellulose microfibrils are susceptible to chemical, enzymatic and mechanical attacks that hydrolyze the amorphous regions in glucose and reduce the crystalline regions into nanocrystalline cellulose (NCC).

NCC results in rigid, rod-shaped monocrystalline cellulose domains (whiskers) which are 5 to $100 \mathrm{~nm}$ in diameter and 10 to $800 \mathrm{~nm}$ in length [11,12]. NCC is still being tested for diversified applications such as: (i) additives for coatings, paints, lacquers, and adhesives, (ii) switchable optical devices, (iii) pharmaceuticals and drug delivery, (iv) bone replacement and tooth repair, (v) improved paper, packaging and building products, (vi) additives for foods and cosmetics, and (vii) aerogels as super insulators. NCC can be chemically modified with other functional groups and conjugated with molecules or nanoparticles giving improved and novel properties. Recently, some emerging bioapplications of functionalized and modified NCC such as drug delivery, enzyme immobilization, nanocatalysis, etc., have been reviewed [13]. Owing to its high mechanical strength, high aspect ratio, large surface area $\left(150-250 \mathrm{~m}^{2} / \mathrm{g}\right)$, and other intriguing electrical and optical properties [14], NCC has been fostered for the preparation of industrial composites. Therefore, the incorporation of a small amount of NCC into plastic and paper could enhance the strength of the latters by several orders of magnitude.

NCC-reinforced plastics have mechanical advantages over conventional automotive plastics, being $30 \%$ lighter and 3-4 times stronger than the currently used materials. They are also less susceptible to damage from heat, chemicals, and spilled gasoline, so they are employed in car parts such as dashboards, bumpers, and side panels. Due to its low toxicity, NCC's environmentally benign nature is the key advantage in driving the development of innovative, sustainable, and recyclable materials [15]. This article aims to explore the application of NCC in the manufacturing of reinforced paper. 
Nanocrystalline cellulose from pretreated biomass, by steam explosion, was obtained through an experimental procedure derived from the literature. This kind of pretreatment is still being studied and optimized as it seems very promising.

The effects of this process are: cleavage of some accessible glycosidic links, cleavage of $\beta$-ether linkages of lignin, cleavage of lignin carbohydrates complex bonds and minor chemical modification of lignin and carbohydrates. Nanocellulose recovery yield obtained by this technique was found to be high compared to other methods [16]. The various colloidal solutions of NCC have been employed to reinforce paper sheets, which have been tested in tensile strength, in durability and in barrier properties.

The possibility to use the NCC for the improvement of several properties of materials has been also largely explored in literature. Concerning the mechanical behavior of both synthetic (e.g., PVOH) and natural (e.g., starch) polymers, a significant increase in the Young's modulus and tensile strength has been demonstrated after treatment with NCC [17]. The improvement of the barrier properties of the membranes has been also experienced in several cases [18,19], addressing the food packaging issue. In addition, using the crystalline content of cellulose matrix seems to be contributory to the development of new biobased prostheses for human wellbeing [20]. Drug delivery and optical iridescence properties are additional fields of constructive applications for NCC [21,22].

A parallel emerging sector is the nanopaper world. There are a limited number of facilities, mainly located in the northern Europe, operative at industrial scale [23] for the combined production of NCC and its incorporation in the common paper pulp in order to produce an increase in resistance and durability of the paper sheets. Such an opportunity should correspond to a reduction of the paper waste volumes, contributing in the sustainability of the production and disposal processes.

In this context, the purpose of the presented research is to demonstrate that the enhancement of the properties of the paper can be obtained also using NCC obtained from residues (e.g., residual biomasses) and not only from dedicated pure cellulosic materials (e.g., cotton, paper, wood, etc.).

\section{Experimental Section}

\subsection{Materials and Methods for NCC Processing}

The following section illustrates the experimental phases of the work including the description of used materials and laboratory procedures.

\subsubsection{Raw Materials}

The experimentation was carried out using the following initial raw materials:

i. Cynara Cardunculus untreated samples

ii. MCC commercial powder

The following paragraph provides a description of the main features of the used materials.

The Cynara Cardunculus samples were firstly characterized using all the equipments that are available at CRB laboratories, using the related quality measurements protocols. In particular, the cellulose, hemicelluloses, acetyl groups, extractives, ashes and lignin components were measured and the results are reported in Table 1. 
The used MCC powder is a commercial product; named MCC CAS 9004-34-6 Alfa Aesar ${ }^{\circledR}$.

Table 1. Main components of the Cynara Cardunculus samples.

\begin{tabular}{cc}
\hline Cynara Cardunculus component & Measured percentage in weight (\% dry basis) \\
\hline Cellulose & $34.96 \pm 0.29$ \\
Hemicelluloses & $16.17 \pm 0.29$ \\
Acetyl groups & $4.54 \pm 0.17$ \\
Extractives & $11.22 \pm 1.08$ \\
Ashes & $7.72 \pm 0.21$ \\
Lignin & $16.89 \pm 0.45$ \\
Other & $4.82 \pm 0.47$ \\
\hline
\end{tabular}

\subsubsection{NCC Produced Samples}

The experimental procedure was applied to produce three different NCC enriched suspensions obtained from the Cynara cardunculus pretreated (by Steam Explosion) and from the cellulose micro crystals (MCC) varying the duration of the ultrasound treatment (further described in Section 2.2). Table 2 summarizes the characteristics of the samples.

Table 2. Characteristics of the liquid cellulose nanocrystals (NCC) samples.

\begin{tabular}{ccc}
\hline Sample name & Input matrix used for extraction & Sonication time (h) \\
\hline NCC cardoon & Cynara cardunculus pretreated by steam explosion & 20 \\
NCC $(10 \mathrm{~h})$ & Commercial MCC & 10 \\
NCC $(5 \mathrm{~h})$ & Commercial MCC & 5 \\
\hline
\end{tabular}

The relative amount of NCC in the obtained liquid suspension was of $1.5 \% \mathrm{w} / \mathrm{w}$.

\subsection{The Extraction Methodology of NCC from Pretreated Biomass}

The extraction methodology consists of a five step protocol allowing the separation of the nanocrystalline content of cellulose. Such a procedure is literary captured [24] with the exception of one step that has been optimized by CRB Lab and it can be applied for the production of NCC from residual biomass and from the micro crystalline cellulose (MCC). In the second case, the procedure was applied starting from Section 2.2.4. Figure 1 shows a picture of the NCC dedicated experimental setup in CRB Labs and Figure 2 is a flow diagram of the experimental procedure.

Figure 1. NCC dedicated setup in Biomass Research Centre (CRB) Labs: (a) hydrolysis reactor and sonication device; (b) dialysis device; (c) centrifuge.
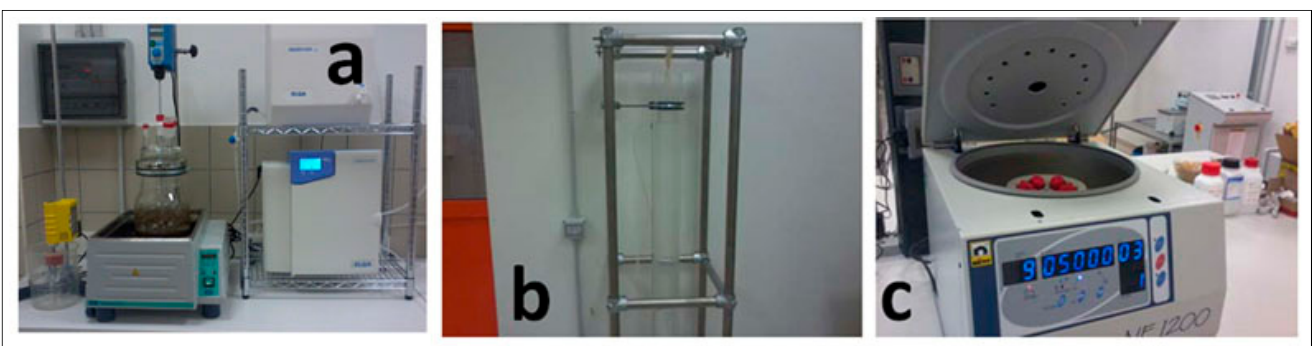
Figure 2. Flow diagram of the experimental procedure carried out by CRB.



2.2.1. Extractives Removal from the Residual Biomass Using the Soxhlet Apparatus [25]

The extractive removal is carried out with a mixture of toluene and ethanol in a 2:1 ratio for $6 \mathrm{~h}$. The thimble containing the residual biomass is cooled at ambient conditions for $6 \mathrm{~h}$ and dried under suction from a vacuum pump to remove the solvent excess. The extractive removal is then further carried out with pure ethanol, to remove traces of toluene under the same conditions as the previous phase. The sample is dried under suction of the vacuum pump for $24 \mathrm{~h}$ in order to remove residual solvents.

\subsubsection{Lignin Separation}

In order to separate lignin from the cellulose component, a basic hydrolysis is carried out applying the conditions described below. The extractive-free biomass is treated with an alkaline solution of sodium hydroxide at $4 \% \mathrm{w} / \mathrm{w}$ with a ratio solvent/residue of $8 / 1(\mathrm{v} / \mathrm{w})$. The operation is conducted at $95{ }^{\circ} \mathrm{C}$ for $2 \mathrm{~h}$. The whole resulting sample is filtered and the liquid component includes the dissolved lignin. The solid part remained into the filter (containing the cellulose component) is washed with deionized water, recovered and dried in air for two days or under suction with a vacuum pump at ambient temperature to reduce the time.

\subsubsection{Energy Bleaching}

The third step involves a processing stage by energy bleaching [1] with sodium chlorite at controlled $\mathrm{pH}$. The sample is rehydrated with $700 \mathrm{~mL}$ of deionized water and placed in a $1 \mathrm{~L}$ flask. It is then preheated to $70{ }^{\circ} \mathrm{C}$ and $1.5 \mathrm{~mL}$ of acetic acid and $6.7 \mathrm{~g}$ of sodium chlorite are added. The sample is maintained under these conditions for $12 \mathrm{~h}$ during which 4 additions of the initial reagents are required $(1.5 \mathrm{~mL}$ of acetic acid and $6.7 \mathrm{~g}$ of sodium chlorite) at regular intervals of about $2.5 \mathrm{~h}$. After the last addition the sample is kept at $70{ }^{\circ} \mathrm{C}$ for $12 \mathrm{~h}$. At the end of the process, a large excess of deionized water is added, the sample is left to decant, and the supernatant is removed. The precipitate 
is recovered, centrifuged and re-washed with deionized water in order to eliminate any trace of the reagents used during the bleaching process.

\subsubsection{Acid Hydrolysis}

After the bleaching process, the sample appears in the form of paper pieces. The fourth step allows the deconstruction of the cellulose into its two components: crystalline and amorphous. Moreover it degrades the latter in order to obtain the nanocrystalline cellulose in acid solution. The obtained sample is inserted into a one-liter flask and $64 \% \mathrm{w} / \mathrm{w}$ sulfuric acid is added so as to obtain a sample/solvent ratio of $1 / 18(\mathrm{w} / \mathrm{v})$. The whole solution is brought to a temperature of $45^{\circ} \mathrm{C}$ and left for $3 \mathrm{~h}$. The reaction is quickly interrupted with cooled deionized water and ice and left to decant overnight in a large bowl. The precipitate matter is than centrifuged and washed with deionized water to regain a neutral solution. The traces of sulfuric acid are removed by dialysis membrane with deionized water in the dedicated apparatus (Figure 1).

\subsubsection{Ultrasound Treatment}

The sample was treated with ultrasound equipment in order to break down NCC agglomerates. In particular, the used ultrasound device is the LABSONIC M-BBI 8535027. This device allowed the continuous treatment at fixed $200 \mathrm{~W}$ power by means of deep probe type $30-750 \mathrm{~mL} / \mathrm{BBI}-8535671$. The duration of the treatment was varied as described in Table 1. Some aliquots were filtered with $0.22 \mu \mathrm{m}$ Nylon filters, dried at $45^{\circ} \mathrm{C}$ for $3 \mathrm{~h}$ and weighed on an analytical balance for NCC quantification. The yield of the process was estimated by comparing the obtained amount of NCC with the cellulose percentage present in the initial residual biomass. Concerning the NCC steps in Sections 2.2.4 and 2.2.5, some experimental procedures using an integrated approach of acid hydrolysis and ultrasonic treatment are available in the literature [26-27].

\subsection{SEM Analysis Methodology}

The experimental procedure used for SEM analysis [28] consisted in the application of the standard test protocol used by the laboratory of the Department of Physics of the University of Perugia [29]. In particular, this methodology is articulated in two phases:

i. $\quad$ samples preparation (i.e., mineralization and arrangement on glass supports);

ii. SEM protocol execution.

Some of the pictures obtained by SEM analysis are presented in the Results and Discussion section.

\subsection{Paper Reinforcement Tests}

The reinforcement properties of the prepared liquid samples were tested according to some relevant ISO standard regulations. The same references were used for the calculation of the significance of the results. The lab tests were carried out by the Laboratory of the Cartiere Fabriano Company. Indeed, the three liquid NCC enriched samples were added to a paper sheet (called linter) by immersion [30]. 
The linter paper sheets were obtained from the conventional paper-making procedure used by Cartiere Fabriano Company and it consists of some organized $\alpha$-cellulose fibers. The characteristics of the untreated material are reported in Tables 4-8. Three different NCC-linter paper sheets were produced, obtained from the three original NCC suspended solutions.

The tests performed over the paper sheets are reported in Table 3:

Table 3. Paper sheet reinforced typologies and type of mechanical test carried out.

\begin{tabular}{|c|c|c|c|c|c|c|}
\hline $\begin{array}{c}\text { Type of } \\
\text { mechanical test }\end{array}$ & U.M. & \multicolumn{4}{|c|}{ Type of sample } & $\begin{array}{c}\text { Standard test } \\
\text { method }\end{array}$ \\
\hline Paper weight & $\mathrm{g} / \mathrm{m}^{2}$ & & \multirow[b]{4}{*}{ 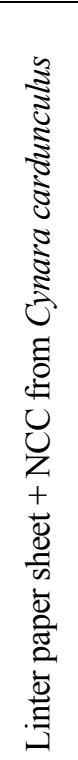 } & \multirow[b]{4}{*}{ 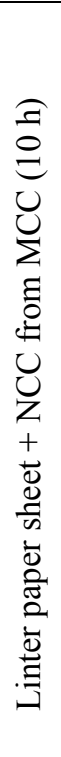 } & \multirow[b]{4}{*}{ 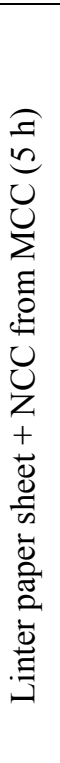 } & ISO 536 \\
\hline Gurley porosity & $\mathrm{s}$ & & & & & ISO 5636/5 \\
\hline Breaking load & $\mathrm{kg} / 15 \mathrm{~mm}$ & & & & & ISO 3781 \\
\hline Bending tests & $\begin{array}{c}\text { Number of } \\
\text { maxima folds }\end{array}$ & 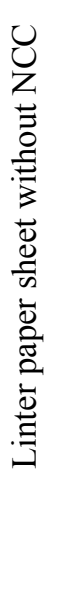 & & & & ISO 5626 \\
\hline
\end{tabular}

\section{Results and Discussion}

\subsection{SEM Analysis}

The three obtained NCC samples were characterized by SEM analysis in order to verify the existence of the nano-crystalline structure. Some SEM images showing the obtained nanostructure are reported in Figures 3 and 4.

Figure 3. SEM image of NCC obtained from Cynara cardunculus.

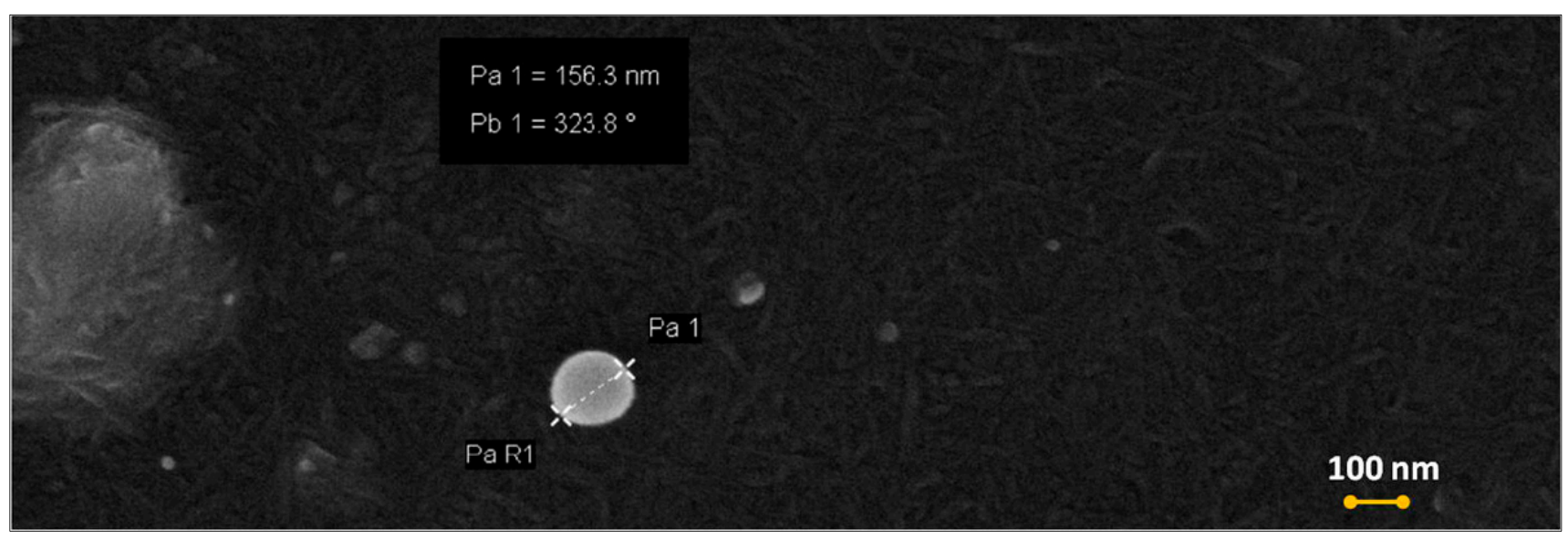


Figure 4. SEM image of NCC obtained from MCC (10 h).

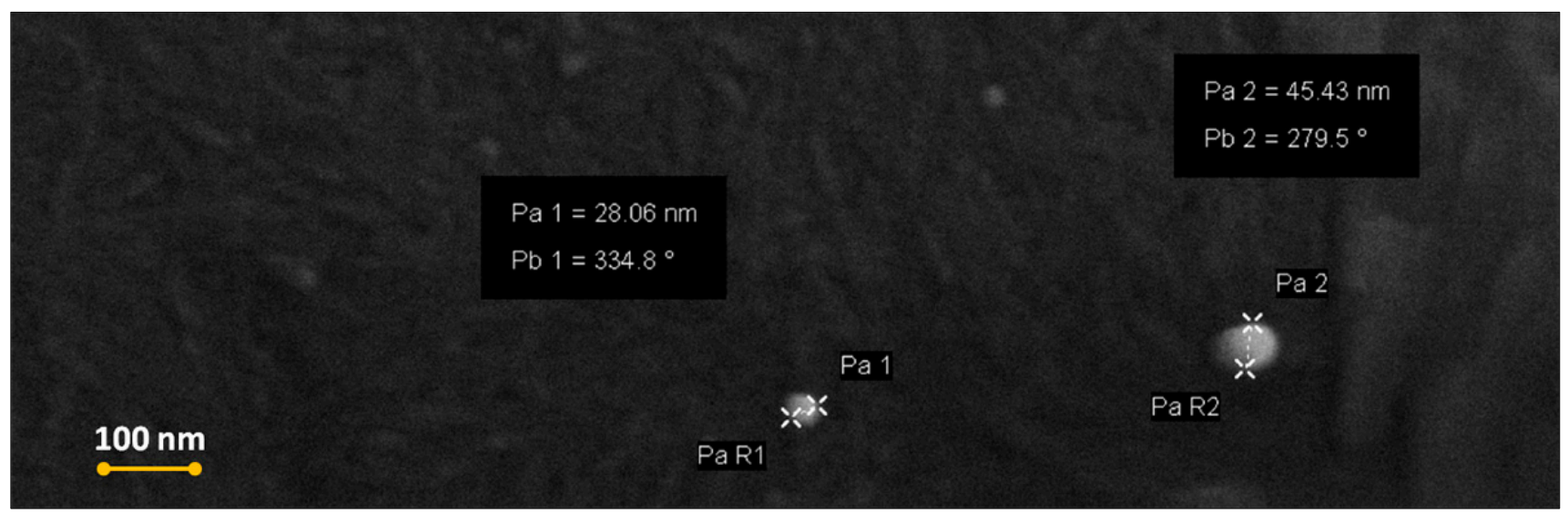

Figures 3 and 4 show a bed of NCC whiskers in the background. The round highlighted elements are some residual agglomerates of cellulose. Although the latter structures are not properly hydrolyzed, they are at nanometric scale. The definition and quality of the nanometric structure is a function of many parameters such as the procedure used to obtain NCC and the control of the regulatory parameters. In addition, the structure of the initial matrix strongly influence the nanometric organization of the NCC particles. Some SEM images of NCC produced from wood pine powder [31], from rice straw and from potato tuber [32] are available. In these images, the NCCs appear more defined and clear.

\subsection{Mechanical Testing}

The following section shows the results obtained from mechanical tests performed on four samples of linter paper sheets (one sample of linter paper sheet and three samples of NCC-linter paper sheets). After immersion [30] of the linter paper sheet into the three different NCC liquid suspensions, the absorption rate was estimated in $0.5 \mathrm{~g} / \mathrm{m}^{2}$ (considering the efficiency of the used film deposition technique) and the size of the cellulose nanocrystals applied as reinforcing filler varies between 10 and $100 \mathrm{~nm}$, as visible from the SEM characterization measures (Figures 3 and 4).

\subsubsection{Paper Weight Tests}

The weight tests were performed in order to assess the parameter variation after treatment. The results are summarized in Table 4.

Table 4. Results of the weight tests before and after the NCC enrichment of the linter paper sheet.

\begin{tabular}{ccccc}
\hline Type of sample & $\begin{array}{c}\text { Linter paper } \\
\text { sheet without } \\
\text { NCC }\end{array}$ & $\begin{array}{c}\text { Linter paper sheet } \\
\text { + NCC from } \\
\text { Cynara cardunculus }\end{array}$ & $\begin{array}{c}\text { Linter paper sheet } \\
\text { + NCC from MCC } \\
\mathbf{( 1 0 ~ h )}\end{array}$ & $\begin{array}{c}\text { Linter paper sheet } \\
\text { + NCC from MCC } \\
\mathbf{( 5 ~ h ) ~}\end{array}$ \\
\hline $\begin{array}{c}\text { Weight measured } \\
\text { value }\left(\mathrm{g} / \mathrm{m}^{2}\right)\end{array}$ & $75.00( \pm 0.01)$ & $75.60( \pm 0.01)$ & $75.30( \pm 0.01)$ & $75.00( \pm 0.01)$ \\
\hline
\end{tabular}


The results shown a light sensible increase in the weight measured value after the NCC enrichment treatment. Concerning the significance of the results, the sensibility of the analytic balance used for performing weight measures introduces an error in the range of $( \pm 0.01)$ on the presented numbers.

\subsubsection{Gurley Porosity Tests}

The barrier properties of the samples were determined by performing several Gurley porosity tests. A known air flux is imposed passing through the surface of each specimen and the time needed to this mass of air to cross the surface is measured. The main results are reported in Table 5. Only one test for each sample was carried out.

Table 5. Gurley porosity tests before and after the NCC enrichment of the linter paper sheet.

\begin{tabular}{ccccc}
\hline Type of sample & $\begin{array}{c}\text { Linter paper } \\
\text { sheet without } \\
\text { NCC }\end{array}$ & $\begin{array}{c}\text { Linter paper sheet } \\
\text { + NCC from } \\
\text { Cynara cardunculus }\end{array}$ & $\begin{array}{c}\text { Linter paper sheet } \\
\text { + NCC from MCC } \\
\mathbf{( 1 0 ~ h )}\end{array}$ & $\begin{array}{c}\text { Linter paper sheet } \\
\text { + NCC from MCC } \\
\mathbf{( 5 ~ h ) ~}\end{array}$ \\
\hline $\begin{array}{c}\text { Gurley porosity } \\
\text { measured value (s) }\end{array}$ & 38 & 45 & 43 & 42 \\
\hline
\end{tabular}

It was found that the NCC enrichment treatment produced a sensible increase in the Gurley porosity value. The porosity improvement was between $10.5 \%$ and $18.4 \%$, and the best result was obtained for linter paper sheet + NCC from Cynara cardunculus.

This result is in agreement with the literature [33] and it is justified by the produced increase in the crystallinity, i.e., the degree of structural order in a solid. In this context, there is also an increasing interest in the barrier properties, due to increased tortuosity provided by nano-particles. Possible interesting applications of NCC relate to barrier membranes. For instance, barrier membranes of poly (vinyl alcohol), PVOH, were studied by Paralikar et al. [34] who have shown how NCC imparts enhancement of both mechanical and barrier properties to these membranes.

\subsubsection{Breaking Load Tests}

The mechanical properties of the prepared samples were measured by performing breaking load tests and repeating the tests four times each sample. The test is carried out by applying a variable load intensity, able to produce an elongation of the specimen equal to $15 \mathrm{~mm}$. The isotropic nature of the linter paper sheets allowed us to choose a casual direction for the application of the load.

Results of the mechanical tests are shown in Table 6 and they were averaged for 4 tests/each sample. The statistical analysis of the results is also reported in Table 7.

Table 6. Breaking load tests before and after the NCC enrichment of the linter paper sheet.

\begin{tabular}{ccccc}
\hline Type of sample & $\begin{array}{c}\text { Linter paper } \\
\text { sheet without } \\
\text { NCC }\end{array}$ & $\begin{array}{c}\text { Linter paper sheet } \\
\text { + NCC from } \\
\text { Cynara cardunculus }\end{array}$ & $\begin{array}{c}\text { Linter paper sheet } \\
\text { + NCC from MCC } \\
\mathbf{( 1 0 ~ h )}\end{array}$ & $\begin{array}{c}\text { Linter paper sheet } \\
\text { + NCC from MCC } \\
\mathbf{( 5 ~ h ) ~}\end{array}$ \\
\hline $\begin{array}{c}\text { Tensile strength } \\
(\mathrm{kg} / 15 \mathrm{~mm})\end{array}$ & 3.69 & 3.98 & 3.72 & 3.69 \\
\hline
\end{tabular}


After statistical evaluations, the obtained results appeared acceptable and significant. In particular, the results demonstrated a sensible increase of the $7.9 \%$ in the measured tensile strength for the sample Linter paper sheet + NCC from Cynara cardunculus and of the $0.8 \%$ for the sample Linter paper sheet $+\mathrm{NCC}$ from MCC $(10 \mathrm{~h})$, while not significant improvement for this parameter was measured for the Linter paper sheet + NCC from MCC (5 h) sample.

Table 7. Statistical analysis of the breaking load tests before and after the NCC enrichment of the linter paper sheet.

\begin{tabular}{lcccc}
\hline Type of sample & $\begin{array}{c}\text { Linter paper } \\
\text { sheet without } \\
\text { NCC }\end{array}$ & $\begin{array}{c}\text { Linter paper sheet } \\
\text { + NCC from } \\
\text { Cynara cardunculus }\end{array}$ & $\begin{array}{c}\text { Linter paper sheet } \\
\text { + NCC from MCC } \\
\mathbf{( 1 0 ~ h )}\end{array}$ & $\begin{array}{c}\text { Linter paper sheet } \\
\text { + NCC from MCC } \\
\mathbf{( 5 ~ h ) ~}\end{array}$ \\
\hline Number of measures & 4 & 4 & 4 & 4 \\
Variance $\left(\sigma^{2}\right)$ & 0.0137 & 0.0019 & 0.0139 & 0.0134 \\
Standard deviation $(\sigma)$ & 0.1170 & 0.0436 & 0.1179 & 0.1158 \\
\hline
\end{tabular}

There has been significant research in the use of NCC to reinforce natural polymers, e.g., starch and produce all bio-based nanocomposites, fully biodegradables and renewable: it has been for instance demonstrated that starch-based polymers can be reinforced by the addiction of a percentage of NCC as filler, as observed by Cao et al. [35].

\subsubsection{Bending Tests}

The durability properties of the prepared samples were measured by performing one bending test for each sample since the test is destructive.

The number of maxima folds before disruption were computed. The results of bending tests were summarized in Table 8.

Table 8. Results of the Bending tests before and after the NCC enrichment of the linter paper sheet.

\begin{tabular}{ccccc}
\hline Type of sample & $\begin{array}{c}\text { Linter paper } \\
\text { sheet without } \\
\text { NCC }\end{array}$ & $\begin{array}{c}\text { Linter paper sheet }+ \\
\text { NCC from } \\
\text { Cynara cardunculus }\end{array}$ & $\begin{array}{c}\text { Linter paper sheet } \\
+ \text { NCC from MCC } \\
(\mathbf{1 0 ~ h )}\end{array}$ & $\begin{array}{c}\text { Linter paper sheet } \\
\text { + NCC from MCC } \\
\mathbf{( 5 ~ h ) ~}\end{array}$ \\
\hline $\begin{array}{c}\text { Bending measured } \\
\text { value (number) }\end{array}$ & 95 & 141 & 101 & 95 \\
\hline
\end{tabular}

The results demonstrated a sensible increase in the observed bending behavior for samples Linter paper sheet + NCC from Cynara cardunculus (plus 48\% in bending measured value) and Linter paper sheet + NCC from MCC (10 h) (plus 6.3\% in bending measured value), while not significant improvement for this parameter was measured for the Linter paper sheet + NCC from MCC $(5 \mathrm{~h})$ sample. This positive result is a consequence of the measured improvement of the mechanical properties of reinforced linter paper sheets.

The results presented in Tables $4-8$ can be probably justified by the hydrogen bonding and gel swelling properties of NCC used as filler of a natural polymer and in the presence of water, as already 
observed in literature [36]; correspondently, the water uptake capacity is expected to decrease referring to the untreated material.

\section{Conclusions}

The possibility to enhance the mechanical, barrier and durability properties of a paper sheet using NCC was presented. An experimental procedure was applied to produce NCC from Cynara cardunculus and from commercial MCC. The results showed a significant increase in these properties for the investigated samples. Some opportunities for scaling-up the process to a pre-commercial stage will be considered as future development of the research since the paper industry is going to the nano-paper world in order to save resources and increase durability and sustainability of their processes. In this context, a major contributory task could be represented by the further enhancement of biorefinery, obtaining high quality products, e.g., NCC from bio-residues. Moreover the future experimental campaign is dedicated to the development of a new green extraction procedure, using ionic liquids instead of acids as medium agents.

\section{Acknowledgments}

The authors would like to acknowledge the Cartiere Fabriano laboratories for their availability to jointly develop the research.

\section{Author Contributions}

Franco Cotana took part to the work as scientific coordinator of the CIRIAF/CRB research group; he provided the guidelines and the research goals to be disclosed. Gianluca Cavalaglio, as responsible of the Laboratory equipments, supervised the whole work. Valentina Coccia and Alessandro Petrozzi wrote a part of the context background and analized the results. Mattia Gelosia carried out the lab procedures and wrote some contributory paragraphs.

\section{Conflicts of Interest}

The authors declare no conflict of interest.

\section{References}

1. Marques, G.; del Río, J.C.; Gutiérrez, A. Lipophilic extractives from several nonwoody lignocellulosic crops (flax, hemp, sisal, abaca) and their fate during alkaline pulping and TCF/ECF bleaching. Bioresource Technol. 2010, 101, 260-267.

2. Oksman, K.; Etang, J.A.; Mathew, A.P.; Jonoobi, M. Cellulose nanowhiskers separated from a bio-residue from wood bioethanol production. Biomass Bioenergy 2011, 35, 146-152.

3. Pirani, S.; Hashaikeh, R. Nanocrystalline cellulose extraction process and utilization of the byproduct for biofuels production. Carbohyd. Polym. 2013, 93, 357-363.

4. Cotana, F.; Cavalaglio, G.; Gelosia, M.; Nicolini, A.; Coccia, V.; Petrozzi, A. Production of bioethanol in a second generation prototype from pine wood chips. Energy Procedia 2014, 45, $42-51$. 
5. Messineo, A.; Volpe, R.; Asdrubali, F. Evaluation of Net Energy Obtainable from Combustion of Stabilised Olive Mill By-Products. Energies 2012, 5, 1384-1397.

6. Beatrice, C.; Di Blasio, G.; Lazzaro, M.; Cannilla, C.; Bonura, G.; Frusteri, F.; Asdrubali, F.; Baldinelli, G.; Presciutti, A.; Fantozzi, F.; et al. Technologies for energetic exploitation of biodiesel chain derived glycerol: Oxy-fuels production by catalytic conversion. Appl. Energ. 2013, 102, 63-71.

7. Blanch, H.W.; Wilke, C.R. Sugars and chemicals from cellulose. Rev. Chem. Eng. 1982, 1, 71-119.

8. Gani, A.; Naruse, I. Effect of cellulose and lignin content on pyrolysis and combustion characteristics for several types of biomass. Renewable Energ. 2007, 32, 649-661.

9. Da Costa, L.; Chundawat, S.; Balan, V.; Dale, B. "Cradle to Grave" assessment of existing lignocellulose pretreatment technologies. Curr. Opin. Biotechnol. 2009, 20, 339-347.

10. Hendriks, A.; Zeeman, G. Pretreatments to enhance the digestibility of lignocellulosic biomass. Bioresource Technol. 2009, 100, 10-18.

11. Ruiz, M.M.; Cavaillé, J.Y.; Dufresne, A.; Gérard, J.F.; Graillat, C. Processing and characterization of new thermoset nanocomposites based on cellulose whiskers. Compos. Interfaces 2000, 7, 117-131.

12. De Souza Lima, M.M.; Borsali, R. Rodlike Cellulose microcrystals: structure, properties, and applications. Macromol. Rapid Commun. 2004, 25, 771-787.

13. Lam, E.; Male, K.B.; Chong, J.H.; Leung, A.C.W.; Luong, J.H.T. Applications of functionalized and nanoparticle-modified nanocrystalline cellulose. Trends Biotechnol. 2012, 30, 283-290.

14. Revol, J.-F.; Godbout, L.; Gray, D.G. Solid films of cellulose with chiral nematic order and optically variable properties. J. Pulp. Pap. Sci. 1998, 24, 146-149.

15. Leung, A.C.W.; Lam, E.; Chong, J.; Hrapovic, S.; Luong, J.H.T. Reinforced plastics and aerogels by nanocrystalline cellulose. J. Nanopart Res. 2013, 15, 1636.

16. Abdul Khalil, H.P.S.; Bhat, A.H.; Ireaan Yusra, A.F. Green composites from sustainable cellulose nanofibrils: A review. Carbohyd. Polym. 2011, 87, 963-979.

17. Bismarck, A.; Mishra, S.; Lampke, T. Plant fibers as reinforcement for green composites. In Nat. Fibers, Biopoly. and Biocomposites; Monhanty, A.K., Misra, M., Drzai, L.T., Eds.; CRC Press: Bota Raton, FL, USA, 2005; pp. 37-108.

18. Liu, A.; Walther, A.; Ikkala, O.; Belova, L.; Berglund, L.A. Clay nanopaper with tough cellulose nanofiber matrix for fire retardancy and gas barrier functions. Biomacromolecules 2011, 12, 633-641.

19. Liu, A.; Berglund, L.A. Clay nanopaper composites of nacre-like structure based on montmorillonite and cellulose nanofibers-Improvements due to chitosan addition. Carbohyd. Polym. 2012, 87, 53-60.

20. Klemm, D.; Kramer, F.; Moritz, S.; Lindström, T.; Ankerfors, M.; Gray, D.; Dorris, A. Nanocelluloses: A new family of nature-based materials. Angew. Chem. Int. Ed. 2011, 50, 5438-5466.

21. Jackson, J.K.; Letchford, K.; Wasserman, B.Z.; Ye, L.; Hamad, W.Y.; Burt, H.M. The use of nanocrystalline cellulose for the binding and controlled release of drugs. Int. J. Nanomedicine 2011, 6, 321-330.

22. Pisello, A.L.; Cotana, F.; Nicolini, A.; Buratti, C. Effect of dynamic characteristics of building envelope onthermal-energy performance in winter conditions: In field experiment. Energ. Buildings 2014, 80, 218-230. 
23. Pilot plant for nanocellulose. Available online: http://www.innventia.com/en/Our-Ways-ofWorking/Demonstration-and-pilot/Pilot-plant-for-nanocellulose/ (accessed on 28 July 2014).

24. Habibi, Y.; Lucia, L.A.; Rojas, O.J. Cellulose Nanocrystals: Chemistry, Self-Assembly, and Applications. Chem. Rev. 2010, 110, 3479-3500.

25. Fantozzi, F.; Barbanera, M.; Bartocci, P.; Massoli, S.; Buratti, C. Caratterizzazione delle biomasse Il laboratorio del CRB. La Termotecnica 2008, 6, 56-60.

26. Chen, W.; Yu, H.; Liu, Y.; Hai, Y.; Zhang, M.; Chen, P. Isolation and characterization of cellulose nanofibers from four plant cellulose fibers using a chemical-ultrasonic process. Cellulose 2011, 18, 433-442.

27. Tang, Y.; Yang, S.; Zhang, N.; Zhang, J. Preparation and characterization of nanocrystalline cellulose via low-intensity ultrasonic-assisted sulfuric acid hydrolysis. Cellulose 2014, 21, 335-346.

28. McMullan, D. Scanning electron microscopy 1928-1965. Scanning 1995, 17, 175-185.

29. SEM protocol UNIPG. Available online: http://www.fisica.unipg.it/dip/servizi-informatici?q= howtoer\&howto $=$ sem\# (accessed on 28 July 2014).

30. Puetz, J.; Aegerter, M.A. Dip coating technique. Sol-Gel Technol. Glass Prod. Users 2004, 2, 37-48.

31. Abe, K.; Iwamoto, S.; Yano, H. Obtaining cellolose nanofibers with a uniform width on $15 \mathrm{~nm}$ from wood. Biomacromolecules 2007, 8, 3276-3278.

32. Abe, K.; Yano, H. Comparison of the characteristics of cellulose microfibril aggregates of wood, rice straw and potato tuber. Cellulose 2009, 16, 1017-1023.

33. Zhou, D.; Tang, Y.; Zhang, N.; Zhang, J.; Liu, D. Effect of various cellulose derivatives on the properties of pigment coatings: A comparative study. Dig. J. Nanomater. Bios. 2014, 9, 305-315.

34. Paralikar, S.A.; Simonsen, J.; Lombard, J. Poly (vinyl alcohol)/cellulose nanocrystals barrier membranes. J. Membr. Sci. 2008, 320, 248-258.

35. Cao, X.; Chen, Y.; Chang, P.R.; Stumborg, M.; Huneault, M.A. Green composites reinforced with hemp nanocrystals in plasticized starch. J. Appl. Polym. Sci. 2008, 109, 3804-3810.

36. Huq, T.; Salmieri, S.; Khan, A.; Khan, R.A.; Le Tien, C.; Riedl, B.; Fraschini, C.; Bouchard, J.; Uribe-Calderon, J.; Kamal, M.R.; et al. Anocrystalline cellulose (NCC) reinforced alginate based biodegradable nanocomposite film. Carbohyd. Polym. 2012, 90, 1757-1763.

(C) 2014 by the authors; licensee MDPI, Basel, Switzerland. This article is an open access article distributed under the terms and conditions of the Creative Commons Attribution license (http://creativecommons.org/licenses/by/3.0/). 